\title{
Mechanical Behavior of Shale Rock under Uniaxial Cyclic Loading and Unloading Condition
}

\author{
Baoyun Zhao $\mathbb{C D}^{1,2,3}$ Dongyan Liu, ${ }^{1,3}$ Ziyun Li $\mathbb{D}^{1,3}$ Wei Huang, ${ }^{1,3}$ and Qian Dong ${ }^{1,3}$ \\ ${ }^{1}$ School of Civil Engineering and Architecture, Chongqing University of Science and Technology, Chongqing 401331, China \\ ${ }^{2}$ Department of Civil and Environmental Engineering, North Dakota State University, Fargo, ND 58108-6050, USA \\ ${ }^{3}$ Chongqing Key Laboratory of Energy Engineering Mechanics \& Disaster Prevention and Mitigation, Chongqing 401331, China
}

Correspondence should be addressed to Baoyun Zhao; baoyun666@163.com

Received 2 October 2017; Revised 1 January 2018; Accepted 8 February 2018; Published 19 March 2018

Academic Editor: Hang Lin

Copyright (C) 2018 Baoyun Zhao et al. This is an open access article distributed under the Creative Commons Attribution License, which permits unrestricted use, distribution, and reproduction in any medium, provided the original work is properly cited.

In order to investigate the mechanical behavior of shale rock under cyclic loading and unloading condition, two kinds of incremental cyclic loading tests were conducted. Based on the result of the short-term uniaxial incremental cyclic loading test, the permanent residual strain, modulus, and damage evolution were analyzed firstly. Results showed that the relationship between the residual strains and the cycle number can be expressed by an exponential function. The deformation modulus $E_{50}$ and elastic modulus $E_{S}$ first increased and then decreased with the peak stress under the loading condition, and both of them increased approximately linearly with the peak stress under the unloading condition. On the basis of the energy dissipation, the damage variables showed an exponential increasing with the strain at peak stress. The creep behavior of the shale rock was also analyzed. Results showed that there are obvious instantaneous strain, decay creep, and steady creep under each stress level and the specimen appears the accelerated creep stage under the 4th stress of 51.16 MPa. Based on the characteristics of the Burgers creep model, a viscoelastic-plastic creep model was proposed through viscoplastic mechanics, which agrees very well with the experimental results and can better describe the creep behavior of shale rock better than the Burgers creep model. Results can provide some mechanics reference evidence for shale gas development.

\section{Introduction}

Rock mass in underground is exposed to systematic cyclic loading during drilling, mechanical excavation, or due to mine seismology [1]. It is clear that the mechanical properties of rock under cyclic loading differ dramatically from those under static loads $[2,3]$. Therefore, it is necessary to understand the response of rock mass under cyclic loading condition.

Laboratory testing is the main method to understand the mechanical behaviors of rock mass. Over the past few decades, considerable efforts have been made to assess the mechanical response of rock under cyclic loads. Liu et al. [4] investigated the deformation and fracture of coal rock under a cyclic loading and unloading condition. By proposing a new incremental cyclic loading-unloading pressure test method, Qiu et al. [5] analyzed experimentally the prepeak unloading damage evolution characteristics of marble from the Jinping
II Hydropower Project. Tien et al. [6] studied deformation and fatigue behaviors of saturated sandstone subjected to cyclic loadings. Based on the load-unload response ratio (LURR) by the multilevel amplitude cyclic loading tests under the different confining pressure, Sun et al. [7] analyzed the damage evolution law and damage accumulation mode of sandstone. Fuenkajorn and Phueakphum [8] investigated the effect of cyclic loading on the mechanical properties of Maha Sarakham salt and found that the salt compressive strength decreased with the number of loading cycles according to a power function and that the elastic modulus decreased slightly during the first few cycles and kept constant until failure.

It is noteworthy that the abovementioned studies mainly focus on the mechanical behavior of rock under cyclic compressive loading and unloading condition and that while the instability of many geotechnical engineering does not appear immediately, such as underground excavation, 
mining tunnel, and drilling, it will last for some time after excavation. So, it is also very necessary to consider the timedependent mechanical behavior of rock mass under cyclic loading.

Shale rock may suffer cyclic loading during drilling, fracturing, and refracturing. To better understand the mechanical behavior of rock mass, the short-term and creep tests of a type of shale rock were conducted under uniaxial cyclic loading. Based on the short-term experimental test results, the deformation, modulus, and damage evolution were first analyzed. Then, in accordance with the creep experimental results, the creep behavior of the shale rock was obtained. Finally, by considering the characteristics of the Burgers creep model, a viscoelastic-plastic creep model was proposed through viscoplastic mechanics and its parameters were identified. Results can help better understand the failure mechanism of shale under cyclic loading, which has important practical significance for accurately assessing the effect of hydraulic fracturing and long-term stability of borehole.

\section{Specimens and Methods}

2.1. Specimen Preparation. The specimen used for the cyclic tests in this research was shale rock, a type of soft sedimentary rock, which was sampled from a Longmaxi formation on the east of the Sichuan Basin in China. Longmaxi Shale is the most commercially developed shale gas reservoir in China $[9,10]$.

The natural rock sample with the average unit weight about is $2668 \mathrm{~kg} / \mathrm{m}^{3}$, and with the same bedding orientation (horizontal), the natural water content of the rock sample is about $6 \%$. According to the method suggested by the ISRM [11], the shape of all tested shale rock specimens is cylindrical with $50 \mathrm{~mm}$ in diameter and $100 \mathrm{~mm}$ in length approximately (Figure 1).

2.2. Testing Equipment. Both conventional uniaxial compression experiments and cyclical experiments of specimens were carried out on a TFD-2000 rheology testing system, as shown in Figure 2. The test machine comprises axial loading, confining pressure loading, hydraulic pressure loading, numerical control, and measurement systems. The maximum axial load is $2000 \mathrm{kN}$, and the measurement resolution is $200 \mathrm{~N}$; the maximum axial deformation is $10 \mathrm{~mm}$, and measurement accuracy is $\pm 0.5 \%$. This machine can perform the controlled tests and data acquisition/analysis by computer and robotized operations, which ensures that the tests are analyzed safely, timely, and precisely.

2.3. Testing Procedure. Due to the shale gas pressure and fracturing fluid pressure, the surrounding rock is always subjected to cyclic loading in the development of shale gas field [12]. Two different kinds of uniaxial cyclic loading and unloading tests were conducted in this research, which were short-term uniaxial cyclic compressive loading and unloading test and long-term compressive cyclic creep test, as shown in Figures 3(a) and 3(b), respectively.

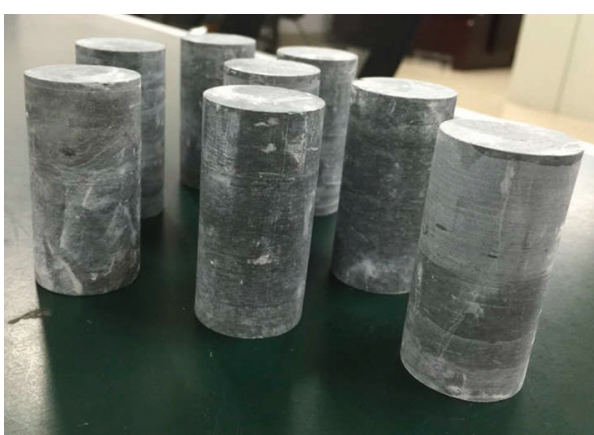

FIGURE 1: Shale rock specimens.

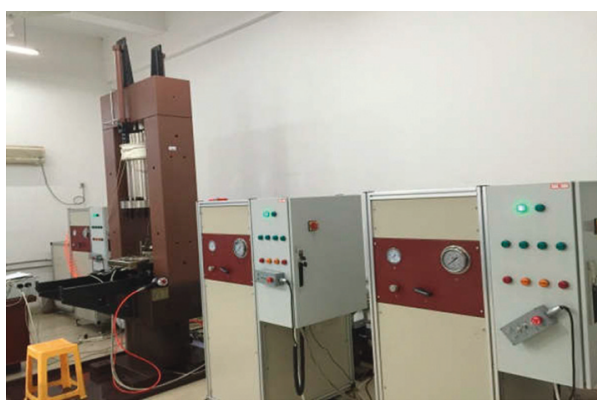

FIgURE 2: TFD-2000 rheology testing system.

Before setting up the testing procedure, the uniaxial compression tests were conducted firstly to obtain the uniaxial compressive strength and the typical stress-strain curve of the shale rock specimen as shown in Figure 4. It can be obtained that the uniaxial compressive strength of the shale rock is $54.32 \mathrm{MPa}$.

The short-term cyclic loading and unloading test (Figure 3(a)) consisted of the following steps. The axial and lateral displacement sensor LVDTs were first adjusted to set the initial value, and then the first loading stress was applied to the designed value; meanwhile, the data of stress, displacement, and strain were recorded by computer software. Next, the stress was unloaded to zero. The preceding steps were repeated until the specimen failed in the last stress level loading process. A constant axial stress control rate of $0.5 \mathrm{MPa} / \mathrm{s}$ was selected during the each loading and unloading stage. In the whole procedure, the first loading stress is $27.16 \mathrm{MPa}$ ( $50 \%$ of the uniaxial compressive strength), and then the stress level was increased by intervals of $8 \mathrm{MPa}$. That is to say, the second to fourth stress levels are $35.16 \mathrm{MPa}, 43.16 \mathrm{MPa}$, and $51.16 \mathrm{MPa}$, respectively.

The procedure for the uniaxial creep test under cyclic loading condition (Figure 3(b)) was as follows. The first loading stress of $27.16 \mathrm{MPa}$ (same as the short-term test) was applied to the specimen at a rate of $0.5 \mathrm{MPa} / \mathrm{s}$ after the displacement sensor LVDTs were first adjusted to set the initial value. Next, the stress was kept constant for a time interval of about 60 minutes, during which the axial deformation was continuously monitored. And then, the axial stress was unloaded to zero at same rate of $0.5 \mathrm{MPa} / \mathrm{s}$. The zero stress level was lasted for about 60 minutes, and then, the second stress will be applied to the specimen. The preceding steps were 


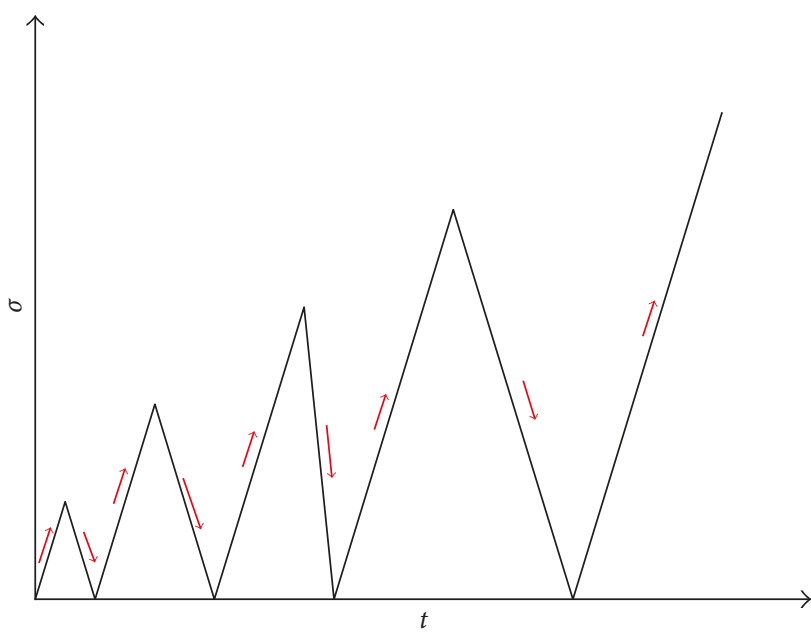

(a)

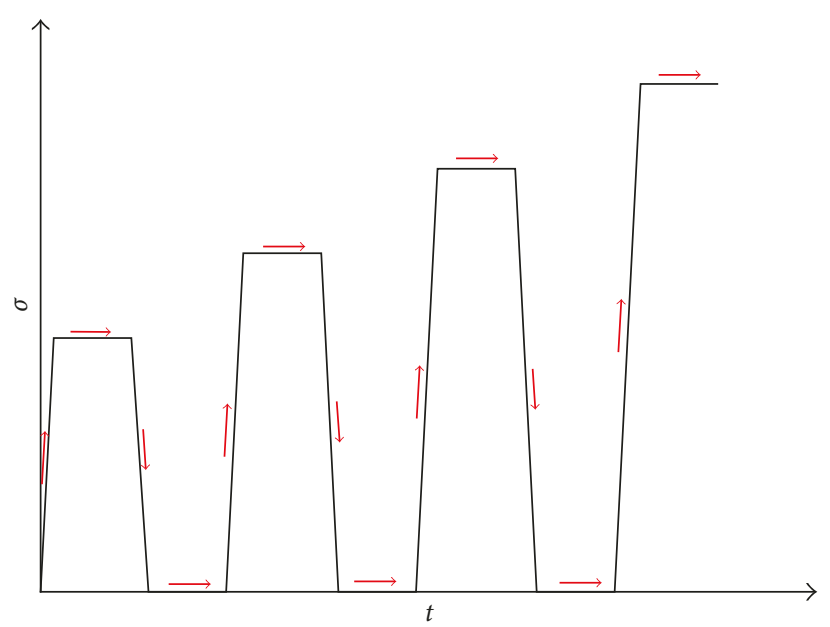

(b)

FIgURE 3: The sketch of (a) short-term cyclic loading test and (b) cyclic loading creep test.

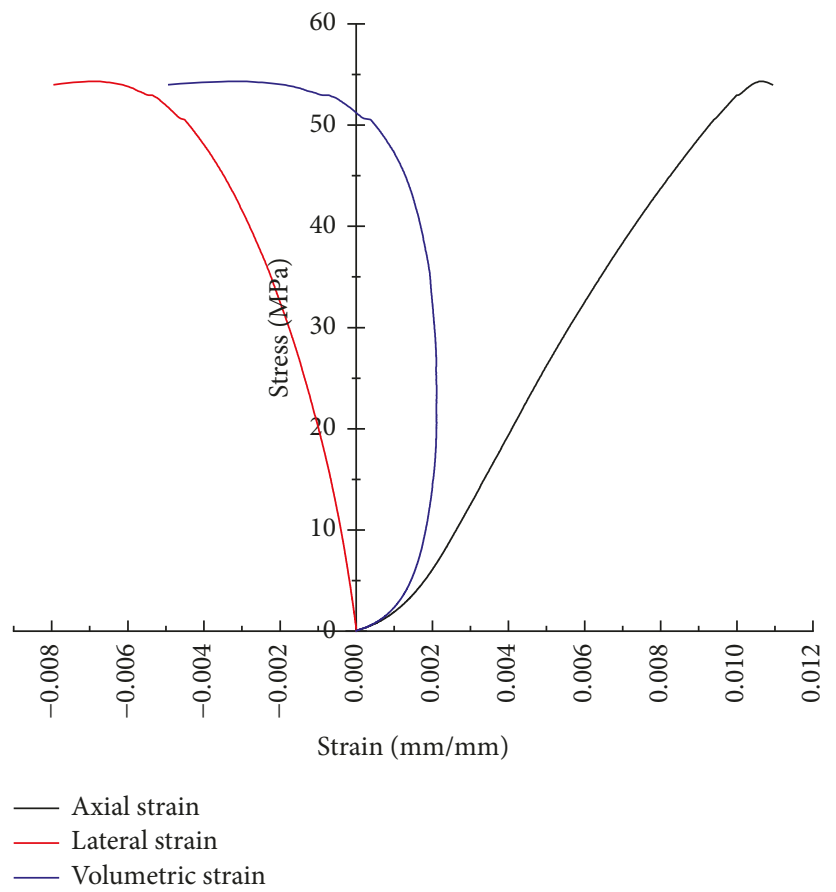

FIGURE 4: The typical stress-strain curve of the shale rock specimen.

repeated until the fourth stress level, and the stress level was also increased by intervals of $8 \mathrm{MPa}$. Finally, at the fifth stress level, the stress was maintained until creep failure took place.

To prevent the effects of variation in diurnal temperature, a constant indoor temperature was maintained at $20 \pm 0.1^{\circ} \mathrm{C}$ during the entire tests.

\section{Experimental Results and Discussion}

\subsection{Mechanical Behavior under Short-Term Cyclic Loading}

3.1.1. Deformation Characteristic. Figure 5 shows the stressstrain curve of the shale rock specimen for a typical cyclic uniaxial test. It can be seen from Figure 5 that the curve of stress-strain formed hysteretic loops after each stress path of compressive loading-compressive unloading, and the area of the hysteretic loops increased with the increasing of the loading stress; this phenomenon is the characteristic of a material where viscosity might play an important role in its stress-strain behavior. It was also found that the stress-strain curve in the compressive loading stages was almost overlapped, which indicated that the stress-strain curve of shale rock has obvious memory effect in the compressive loading stages.

As shown in Figure 5, considerable irreversible deformation of shale rock is observed. Figure 6 shows the relationship between the residual strains and the cycle number. With the increase in the stress levels and cyclic 


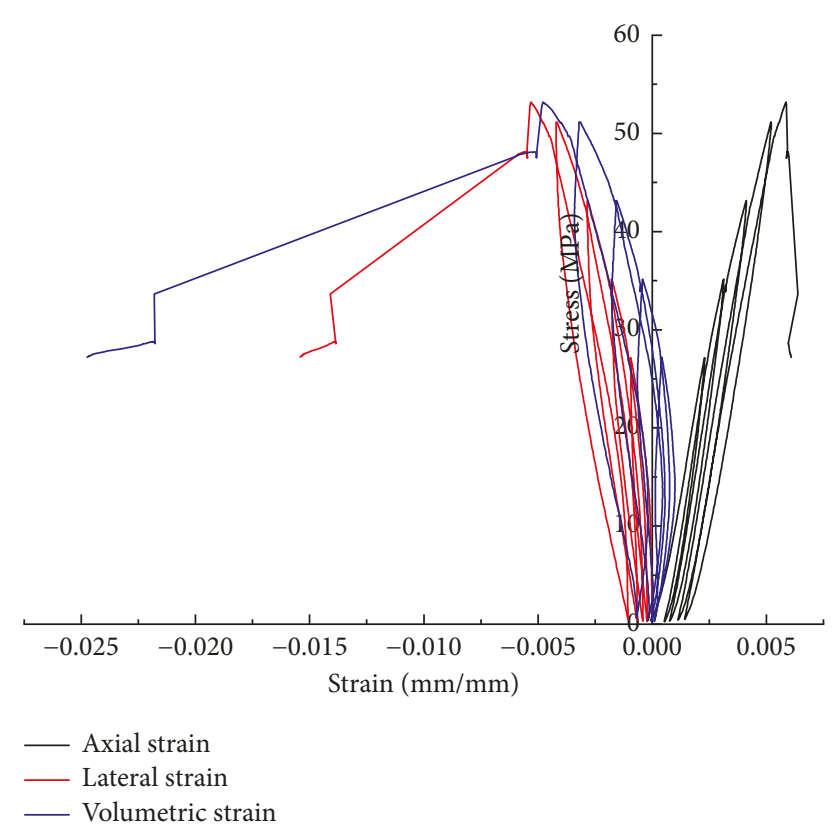

FIGURE 5: Curve of stress-strain under short-term uniaxial cyclic loading condition.

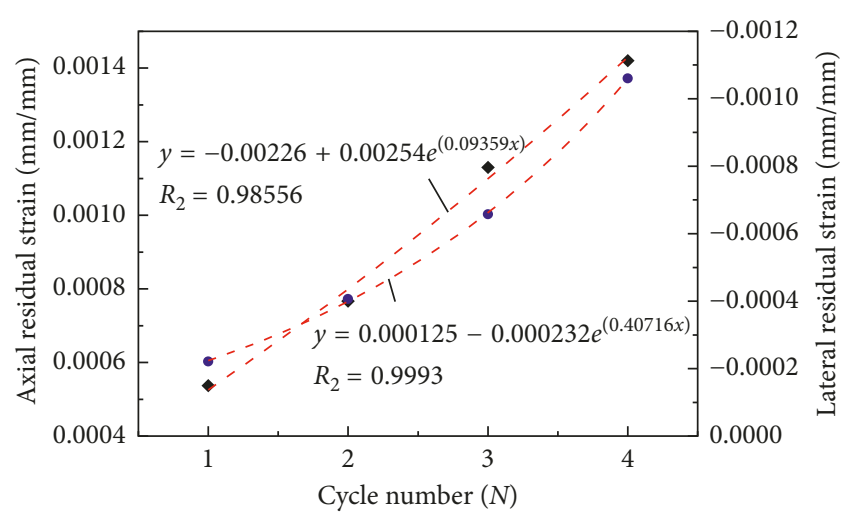

- Axial residual strain

- Lateral residual strain

- - - Fitting curves

Figure 6: Relationship between the residual strain and the cycle number.

loading numbers, the irreversible deformation becomes more significant, and the relationship between the residual strains and the cycle number can be expressed by an exponential function. Meanwhile, the influence of stress levels on the irreversible deformation appears more evident than the cyclic loading numbers.

It can be also obtained that the rupture stress is $53.18 \mathrm{MPa}$, which is $97.91 \%$ of the uniaxial compressive strength. Figure 7 shows a schematic view of the shale rock specimen after failure under uniaxial compressive loading and unloading condition, the main feature associated with the failure is the tension destruction.

3.1.2. Characteristics of Modulus. Figure 8 shows the relationship between peak stress at each cycle loop and elastic

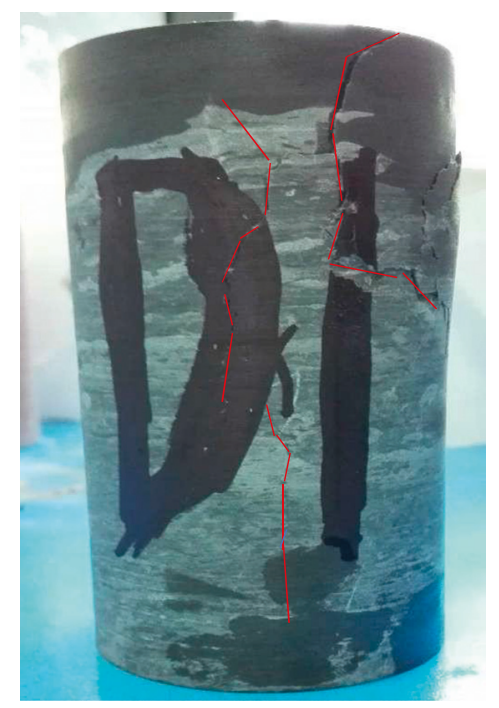

FIgURE 7: Schematic view of the shale rock specimen after failure.

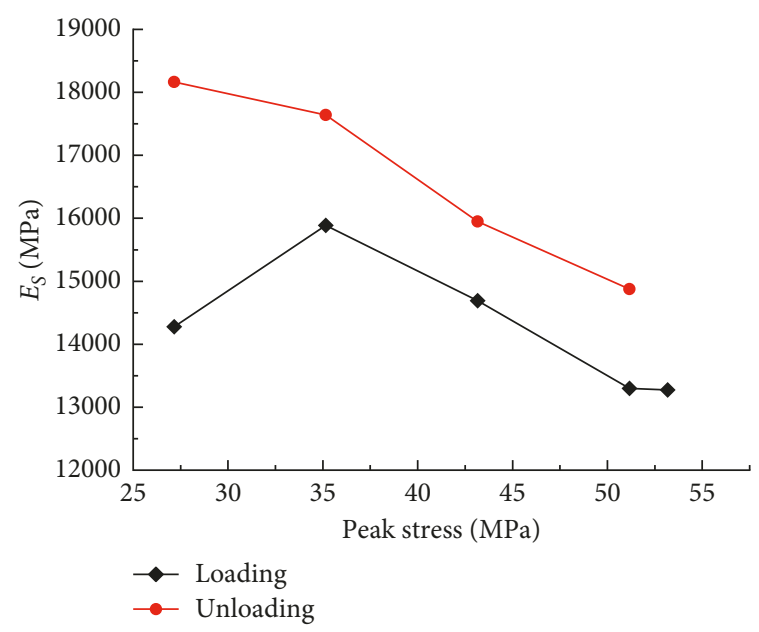

FIGURE 8: Relationship between each peak stress and $E_{S}$.

modulus $E_{S}$. Figure 9 shows the relationship between peak stress and deformation modulus $E_{50}$. It should be claimed that, in Figures 8 and 9, the elastic modulus $E_{S}$ is the slope of the linear segment in the loading or unloading curve [12]. The deformation modulus $E_{50}$ is the slope of the line between the point at which the stress value is $50 \%$ of each loading at the peak strength and the minimum stress point of the coordinates. follows:

The deformation modulus $E_{50}$ can be expressed as

$$
E_{50}=\frac{\sigma_{(1 / 2) p}-\sigma_{\min }}{\varepsilon_{(1 / 2) p}-\varepsilon_{\min }},
$$

where $E_{50}$ is the deformation modulus; $\sigma_{(1 / 2) p}$ and $\varepsilon_{(1 / 2) p}$ are the stress and strain at the point of half peak strength under each cycle loading or unloading section, respectively; and $\sigma_{\min }$ and $\varepsilon_{\min }$ are the stress and strain at the minimum stress point under each cycle loading or unloading section, respectively. 


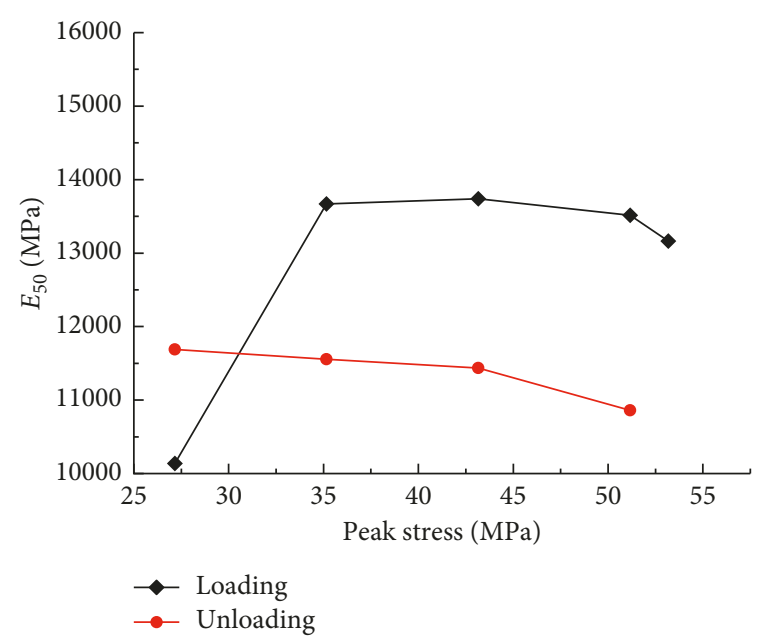

Figure 9: Relationship between each peak stress and $E_{50}$.

The elastic modulus $E_{S}$ can be expressed as follows:

$$
E_{S}=\frac{\Delta \sigma}{\Delta \varepsilon}
$$

where $\Delta \sigma$ is the stress increment on the linear section under each cycle loading or unloading and $\Delta \varepsilon$ is the strain increment which is corresponded to $\Delta \sigma$.

From Figures 8 and 9, the deformation modulus $E_{50}$ and elastic modulus $E_{S}$ first increase and then decrease with increase of peak stress under the loading condition, while the both of them increase approximately linearly with increase of the peak stress under the unloading condition.

\subsubsection{Damage Evolution of Shale Rock under Cyclic Loading.} The existed initial cracks or bedding planes within shale make the quantity of damaged parts increase, and the area expands when the shale is under cyclic loading situation, and the increased damage causes the effective stress on a microscale to increase. All sorts of the mesoscopic flaws in shale rock are randomly distributed because rock is a product of long geological history [13]. Therefore, damage mechanics is a powerful tool to study the occurrence, propagation, and coalescence processes of these mesoscopic flaws and their effect on rock mechanical behaviors. Damage mechanics consists of the study of initiation and propagation of internal microcracks and defects under different loading condition, which may lead to deterioration of the mechanical properties of the material and eventually to failure [14]. To describe the damage evolution process, the calculation of the damage variable is essential.

Based on the stress-strain curve of the rock mass under cyclic loading, we can calculate the constitutive energy and the dissipated energy at a given stress state, as shown in Figure 10. According to the previous studies [14-16], the constitutive energy of the rocks is represented by the area between the complete stress-strain curve and the strain axis, and the area of $\mathrm{OA}_{1} \mathrm{~A}_{1}^{\prime}$ is surrounded by the first loading curve, and the strain axis can be defined as absorbed energy; the area of $\mathrm{O}^{\prime} \mathrm{A}_{1} \mathrm{~A}_{1}^{\prime}$ which is surrounded by the first

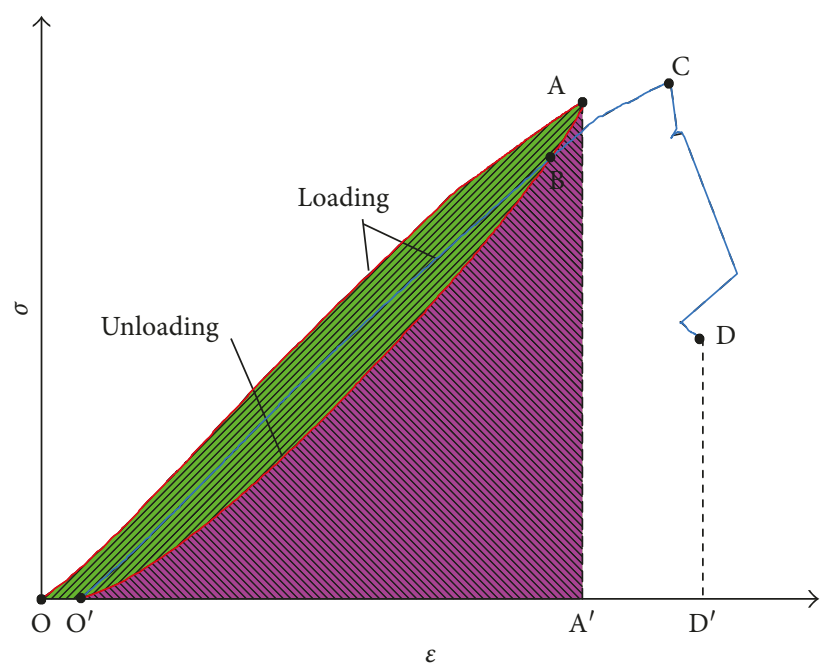

FIGURE 10: Calculation model of dissipated energy and constitutive energy.

unloading curve and the strain axis can be defined as released energy. So, the area of $\mathrm{OAO}^{\prime}$ which is surrounded by the first loading curve, the first unloading curve, and the strain axis can be defined as the dissipated energy. Then the damage variable [14] at point A can be obtained as follows:

$$
D=\frac{U_{\mathrm{OAO}^{\prime}}}{U}=\frac{U_{\mathrm{OA}_{1} \mathrm{~A}_{1}^{\prime}}-U_{\mathrm{O}^{\prime} \mathrm{A}_{1} \mathrm{~A}_{1}^{\prime}}}{U}
$$

where $U_{\mathrm{OAO}^{\prime}}$ is the dissipated energy under first cycle loads; $U_{\mathrm{OA}_{1} \mathrm{~A}_{1}^{\prime}}$ is the absorbed energy under first cycle loads; $U_{\mathrm{O}^{\prime} \mathrm{A}_{1} \mathrm{~A}_{1}^{\prime}}$ is the released energy under first cycle loads; and $U$ is the constitutive energy.

According to the results from cyclic loading test on the shale rock, the damage variable can be calculated by using (3). Figure 11 shows the relationship between the calculated damage variables and the strain at peak stress. An exponential function was used to fit the damage variables of the shale rock, with a coefficient of determination greater than 0.98 .

\subsection{Creep Behavior of the Shale Rock Specimens}

3.2.1. Cyclic Creep Test Results. In accordance with the testing procedure shown in Figure 3(b), the cyclic loading creep test result of shale rock was obtained, as shown in Figure 12. The stress levels were the same as these of shortterm cyclic loading tests, and it was lasted for about 2 hours at each cycle.

It can be deduced from Figure 12 that under stress levels of $27.16 \mathrm{MPa}, 35.16 \mathrm{MPa}$, and $43.16 \mathrm{MPa}$, the axial and lateral strain rate increases first and then gradually decreases to a constant value after a period time, and the similar variance trend was found in the unloading stage. According to the evolution of the creep strain, the creep curve under each stress level can be divided into decaying and steady stages except 4 th stress of $51.16 \mathrm{MPa}$. Both axial instantaneous strain and steady strain of the specimen were increased with compression stress; the residual strains were also appeared 


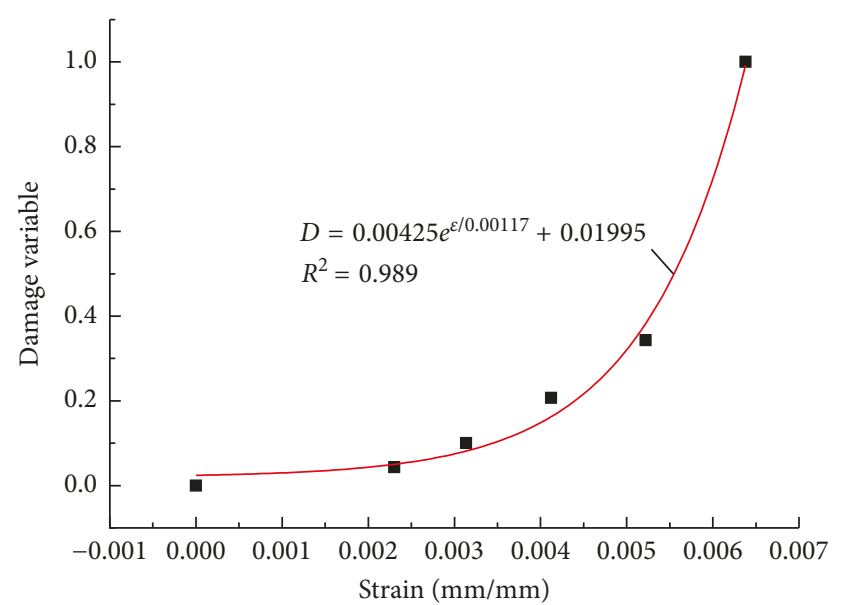

- Experimental results

- Fitting curve

Figure 11: Calculated damage variables of shale rock and its fitted curve.

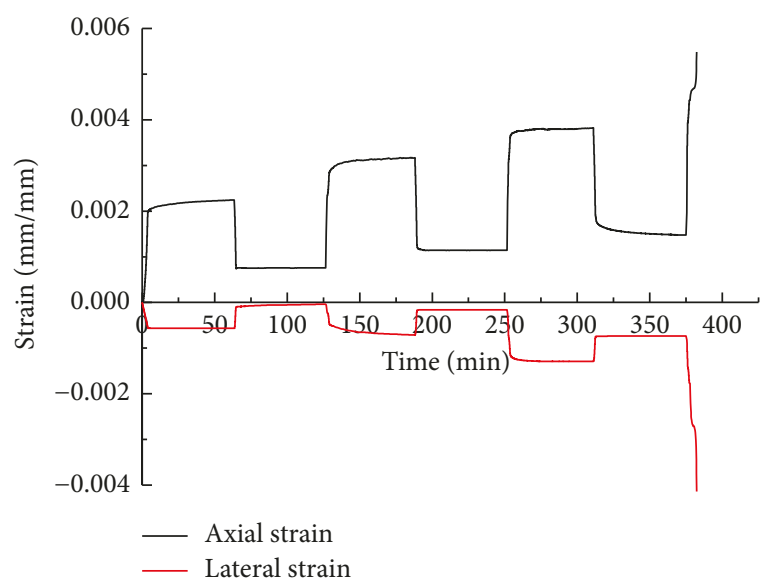

Figure 12: Curves of axial strain versus time of shale rock specimens under cyclic loading.

increase trend with increasing of former stress levels. The rock specimen fails eventually at 4 th stress of $51.16 \mathrm{MPa}$ which is $94.18 \%$ of the uniaxial compressive strength, also lower than the short-term rupture stress $(53.18 \mathrm{MPa})$ indicated that time-dependent cycle loads have a significant impact on the damage evolution of the shale rock, the creep curve at this stress level stage includes three stages of the decaying, steady, and accelerating creep, and the whole creep only lasted for several minutes.

3.2.2. Creep Model and Parameter Identification. Form Figure 12, it can be easily observed that there are obvious instantaneous strain, decay creep, and steady creep under each stress level, and steady creep strain approaches a certain constant value with the time when stress less than $51.16 \mathrm{MPa}$. While under the 4 th stress of $51.16 \mathrm{MPa}$, the specimen shows the accelerated creep stage. Therefore, it is necessary to simulate the creep behavior of rock by using a creep model.

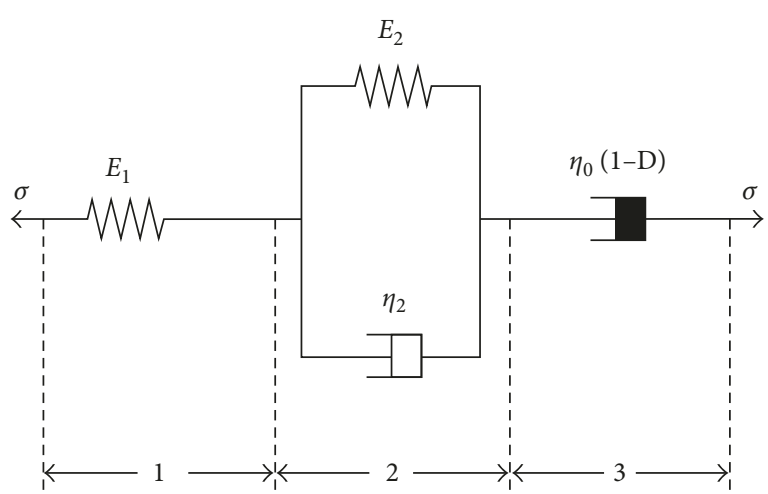

Figure 13: Illustration of the viscoelastic-plastic creep model.

Previous studies have shown that the viscosity coefficient of rock will decrease when stress exceeds the long-term ultimate strength [17-19]; since an exponential function can better reflect the relationship between the damage variables and the strain (Figure 10), we assume that the damage variables in the cycle creep stage can be expressed as an exponential function (as shown in (4)), and based on the characteristic of the Burgers creep model [20], a new viscoelastic-plastic creep model was proposed, as shown in Figure 13.

$$
D=1-\exp \left(-\alpha \frac{t^{\beta}}{t_{0}^{\beta}}\right)
$$

where $\alpha$ and $\beta$ are the parameters controlling the damage evolution with time, which are related to the stress levels and cycle times; $t$ is the creep time; and $t_{0}$ is the unit time, which is 1 minute in this work.

The creep equation of the viscoelastic-plastic creep model can be written as follows:

$$
\varepsilon=\frac{\sigma_{0}}{E_{1}}+\frac{\sigma_{0}}{E_{2}}\left(1-\exp \left(-\frac{E_{2}}{\eta_{2}} t\right)\right)+\frac{\sigma_{0}-\sigma_{\infty}}{\eta_{0}(1-D)} t,
$$

where $\sigma_{0}$ and $\varepsilon$ are creep stress and creep strain, respectively; $E_{1}$ is the elastic modulus of the Maxwell body; and $E_{2}$ and $\eta_{2}$ are the elastic modulus and viscosity coefficient of the Kelvin body, $\eta_{0}$ is the initial value of the viscosity coefficient and $t$ is the creep time.

By using the viscoelastic-plastic creep model (5) to fit the creep curves, the relevant parameters of the viscoelasticplastic creep model were identified from data processing, as shown in Table 1; meanwhile, the Burgers creep model was also used to make a comparison with this of the proposed viscoelastic-plastic creep model. Figure 14 shows the calculated results of creep curves and the tested ones which were below stress level of $51.16 \mathrm{MPa}$, and the fitting curve and tested curve under stress level of $51.16 \mathrm{MPa}$ are shown in Figure 15. From the two figures, it was found that the calculated results of the proposed model are in good agreement with the tested results than the Burgers creep model under each stress level, and the proposed model also can better reflect accelerated creep stage of the shale rock specimen. The correlation coefficient square $\left(R^{2}\right)$ of four curves is more than 0.959 , which indicates that the prediction precision of 
TABle 1: Parameters of the viscoelastic-plastic creep model.

\begin{tabular}{|c|c|c|c|c|c|c|c|}
\hline Stress level (MPa) & $E_{1}(\mathrm{MPa})$ & $E_{2}(\mathrm{MPa})$ & $\eta_{2}(\mathrm{MPa} \cdot \min )$ & $\eta_{0}(\mathrm{MPa} \cdot \min )$ & $\alpha$ & $\beta$ & $R^{2}$ \\
\hline 27.16 & 13667.22 & 120846.50 & 1123865.91 & 3356791.52 & 0.02 & 2.58 & 0.988 \\
\hline 35.16 & 12528.82 & 457903.91 & 2265214.34 & 219.08 & -7.65 & 0.08 & 0.997 \\
\hline 43.16 & 11899.18 & 63875.70 & $1.45 E+16$ & 51177.93 & -2.65 & 0.19 & 0.959 \\
\hline 51.16 & 11520.01 & 432090.97 & 110414.84 & 999684.64 & $-8.34 E-06$ & 7.80 & 0.990 \\
\hline
\end{tabular}

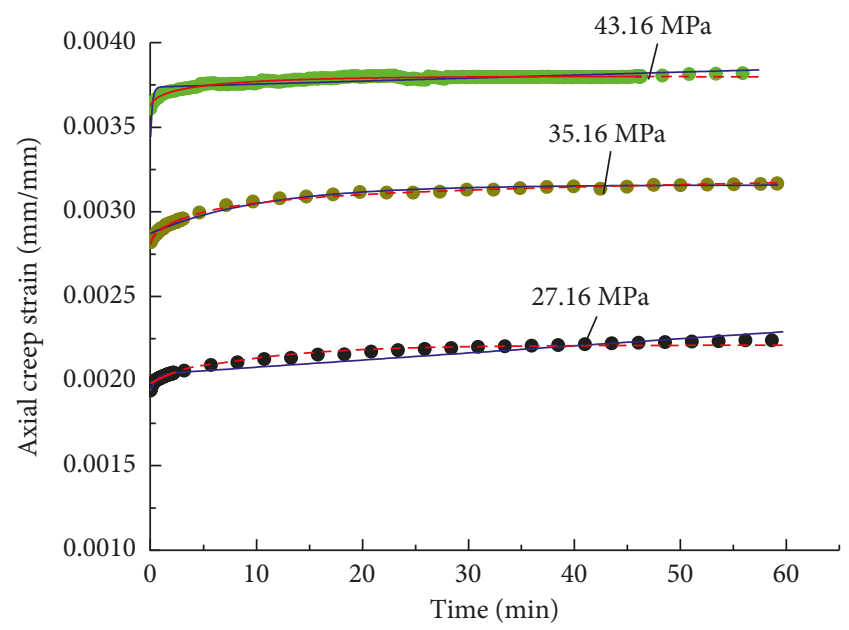

- Experimental curve

- Burgers creep model fitting curve

_ Viscoelastic-plastic creep model fitting curve

Figure 14: Comparison between calculated results and experimental results below the stress level of $51.16 \mathrm{MPa}$.

the proposed model here is high in simulating properties of the shale rock under cyclic loads.

\section{Conclusions}

Two different kinds of cyclic loading and unloading tests were conducted in this study for characterizing the mechanical behavior of shale rock, which were short-term uniaxial incremental compressive cyclic loading and unloading test and long-term uniaxial incremental compressive cyclic loading and unloading creep test. From the test results, the following conclusions can be drawn:

(1) The relationship between the residual strains and the cycle number can be expressed by an exponential function. The deformation modulus and elastic modulus first increase and then decrease with increase of peak stress under the loading condition, and both of them increase approximately linearly with increase of the peak stress under the unloading condition.

(2) The cyclic loads formed hysteretic loops, and the area of the hysteretic loops increased with the increasing of the loading stress, which can be used to interpret energy dissipation of the specimen. Based on the energy dissipation, the damage variables under short-term cyclic loading condition were analyzed, and it shows an exponential increasing with the strain at peak stress.

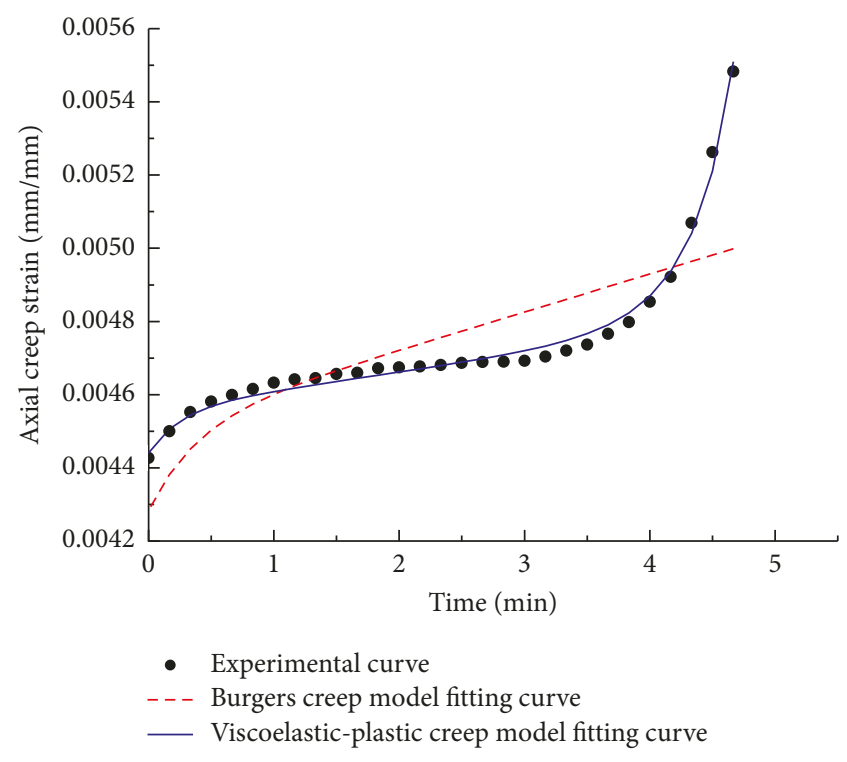

FIGURE 15: Test results and model calculation curves of specimen under stress levels of $51.16 \mathrm{MPa}$.

(3) There exist obvious instantaneous strain, decay creep, and steady creep under each loading or unloading stage, and under the stress of $51.16 \mathrm{MPa}$, the specimen shows the accelerated creep stage.

(4) A viscoelastic-plastic creep model was proposed. Comparison of the test results with the model predictions shows that the proposed viscoelastic-plastic creep model is capable of describing the creep behavior of shale rock subjected to cyclic loading and unloading condition.

Finally, it should be noted that further studies both in triaxial tests and in theory are necessary to gain more relative data for better understanding the cycle load mechanical behavior of shale rock. Numerical simulation of engineering projects associated with shale rock should also be taken into account in the future.

\section{Conflicts of Interest}

The authors declare that there are no conflicts of interest regarding the publication of this paper.

\section{Acknowledgments}

This study was partially supported by the National Natural Science Foundation of China (Grant no. 41302223), Science and Technology Plan Projects of Chongqing Administration 
of Land, Resources and Housing (KJ-2015047), Chongqing No. 3 Colleges and Universities Youth Backbone Teachers Funding Plans and Chongqing Research Program of Basic Research and Frontier Technology (cstc2016jcyjA0074, cstc2016jcyjA0933, and cstc2015jcyjA90012), and Scientific and Technological Research Program of Chongqing Municipal Education Commission (KJ1713327 and KJ1600532). The authors also thank Professor Yang Mijia for his valuable suggestions and English improvement of this manuscript, which comes from Department of Civil and Environmental Engineering, North Dakota State University.

\section{References}

[1] A. Taheri, A. Royle, Z. Yang, and Y. Zhao, "Study on variations of peak strength of a sandstone during cyclic loading," Geomechanics and Geophysics for Geo-Energy and Geo-Resources, vol. 2, no. 1, pp. 1-10, 2016.

[2] A. Momeni, M. Karakus, G. R. Khanlar, and M. Heidari, "Effects of cyclic loading on the mechanical properties of a granite," International Journal of Rock Mechanics \& Mining Sciences, vol. 77, pp. 89-96, 2015.

[3] J. Q. Xiao, D. X. Ding, F. L. Jiang, and G. Xu, "Fatigue damage variable and evolution of rock subjected to cyclic loading," International Journal of Rock Mechanics \& Mining Sciences, vol. 47, no. 3, pp. 461-468, 2010.

[4] X. F. Liu, X. R. Wang, E. Y. Wang, Z. T. Liu, and X. Y. Xu, "Study on ultrasonic response to mechanical structure of coal under loading and unloading condition," Shock and Vibration, vol. 2017, Article ID 7643451, 12 pages, 2017.

[5] S. L. Qiu, X. T. Feng, J. Q. Xiao, and C. Q. Zhang, "An experimental study on the pre-peak unloading damage evolution of marble," Rock Mechanics and Rock Engineering, vol. 47, pp. 401-409, 2014.

[6] Y. M. Tien, D. H. Lee, and C. H. Juang, "Strain, pore pressure and fatigue characteristics of sandstone under various load conditions," International Journal of Rock Mechanics and Mining Sciences \& Geomechanics Abstracts, vol. 27, no. 4, pp. 283-289, 1990.

[7] B. Sun, Z. D. Zhu, C. Shi, and Z. H. Luo, "Dynamic mechanical behavior and fatigue damage evolution of sandstone under cyclic loading," International Journal of Rock Mechanics and Mining Sciences, vol. 94, pp. 82-89, 2017.

[8] K. Fuenkajorn and D. Phueakphum, "Effects of cyclic loading on mechanical properties of Maha Sarakham salt," Engineering Geology, vol. 112, no. 1-4, pp. 43-52, 2010.

[9] T. L Guo and H. R. Zhang, "Formation and enrichment mode of Jiaoshiba shale gas field, Sichuan basin Pet," Petroleum Exploration and Development, vol. 41, no. 1, pp. 28-36, 2014.

[10] Y. L. Kang, M. J. Chen, Z. X. Chen, L. J. You, and Z. W. Hao, "Investigation of formation heat treatment to enhance the multiscale gas transport ability of shale," Journal of Natural Gas Science and Engineering, vol. 35, pp. 65-275, 2016.

[11] C. E. Fairhurst and J. A. Hudson, "Draft ISRM suggested method for the complete stress train curve for the intact rock in uniaxial compression," International Journal of Rock Mechanics and Mining Sciences, vol. 36, no. 3, pp. 279-289, 1999.

[12] Y. L. Wei, C. H. Yang, Y. T. Guo, W. Liu, L. Wang, and S. Heng, "Experimental investigation on deformation and fracture characteristics of brittle shale with natural cracks under uniaxial cyclic loading," Rock and Soil Mechanics, vol. 36, no. 6, pp. 1649-1748, 2015, in Chinese.
[13] H. Y. Liu and L. M. Zhang, “A damage constitutive model for rock mass with nonpersistently closed joints under uniaxial compression," Arabian Journal for Science and Engineering, vol. 40, no. 11, pp. 3107-3117, 2015.

[14] J. F. Liu, H. P. Xie, M. Zheng, H. C. He, and Y. L. Chen, "Damage evolution of rock salt under cyclic loading in uniaxial tests," Acta Geotechnica, vol. 9, no. 1, pp. 153-160, 2014.

[15] H. Munoz, A. Taheri, and E. K. Chanda, "Rock drilling performance evaluation by an energy dissipation based rock brittleness index," Rock Mechanics and Rock Engineering, vol. 49, no. 8, pp. 3343-3355, 2016.

[16] P. Wang, J. Y. Xu, X. Y. Fang, and P. X. Wang, "Energy dissipation and damage evolution analyses for the dynamic compression failure process of red-sandstone after freezethaw cycles," Engineering Geology, vol. 221, pp. 104-113, 2017.

[17] P. Cao, Y. D. Wen, Y. X. Wang, H. P. Yuan, and B. X. Yuan, "Study on nonlinear damage creep constitutive model for high-stress soft rock," Environmental Earth Sciences, vol. 75, no. 10, pp. 1-8, 2016.

[18] L. Z. Wu, B. Li, R. Q. Huang, and P. Sun, "Experimental study and modeling of shear rheology in sandstone with nonpersistent joints," Engineering Geology, vol. 222, pp. 201211, 2017.

[19] H. Z. Liu, H. Q. Xie, J. D. He, M. L. Xiao, and L. Zhuo, "Nonlinear creep damage constitutive model for soft rocks," Mechanics of Time-Dependent Materials, vol. 21, pp. 73-96, 2017.

[20] L. S. Gao, H. C. Dan, and J. Q. Chen, "Research on predicting the rutting of asphalt pavement based on a simplified burgers creep model," Mathematical Problems in Engineering, vol. 2017, Article ID 3459704, 14 pages, 2017. 


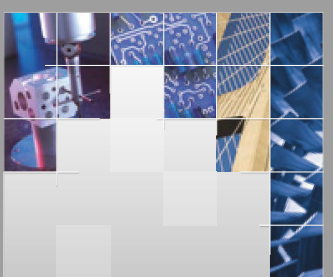

\section{Enfincering}
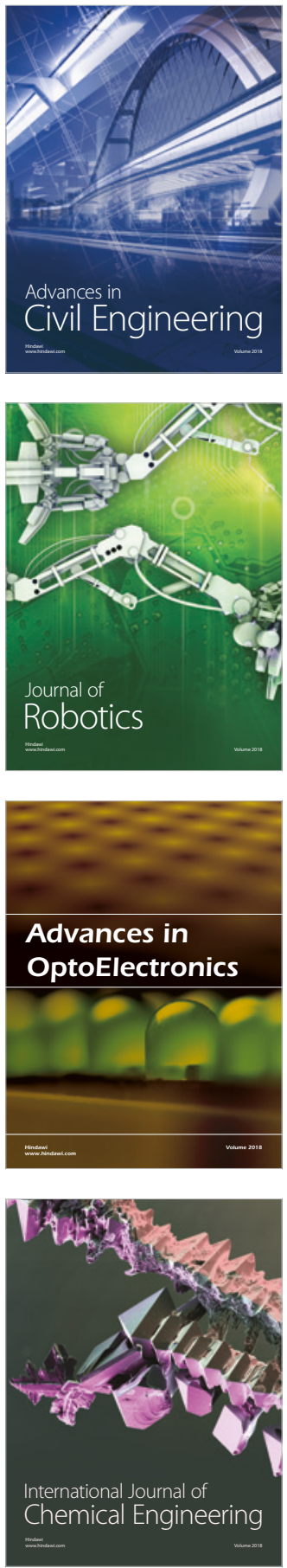

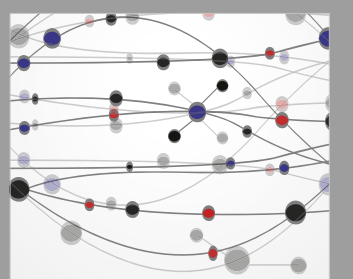

\section{Rotating \\ Machinery}

The Scientific World Journal

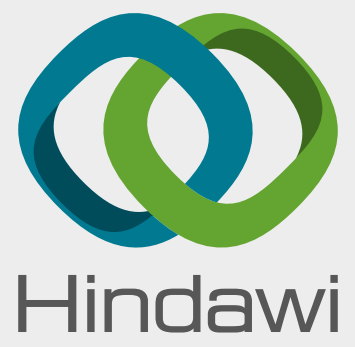

Submit your manuscripts at

www.hindawi.com
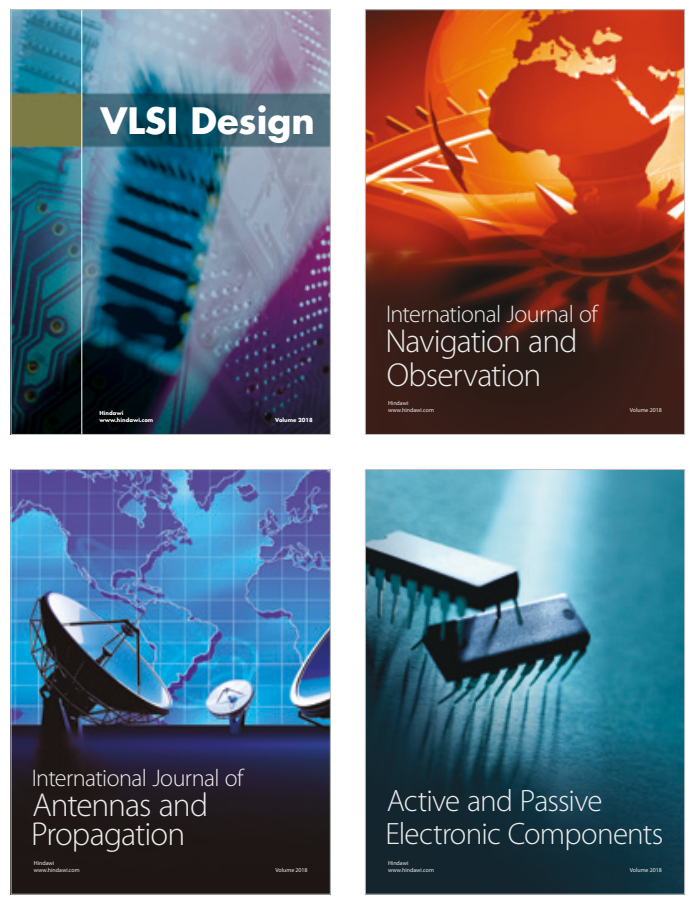
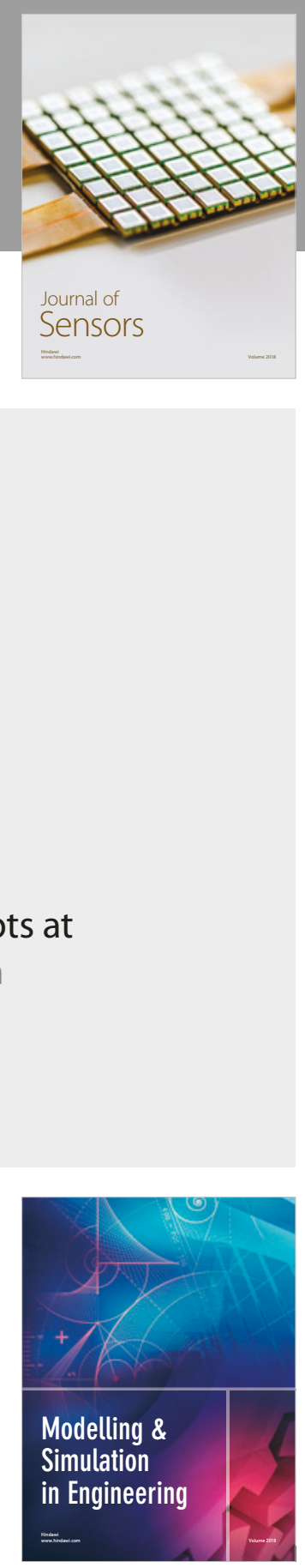

\section{Advances \\ Multimedia}
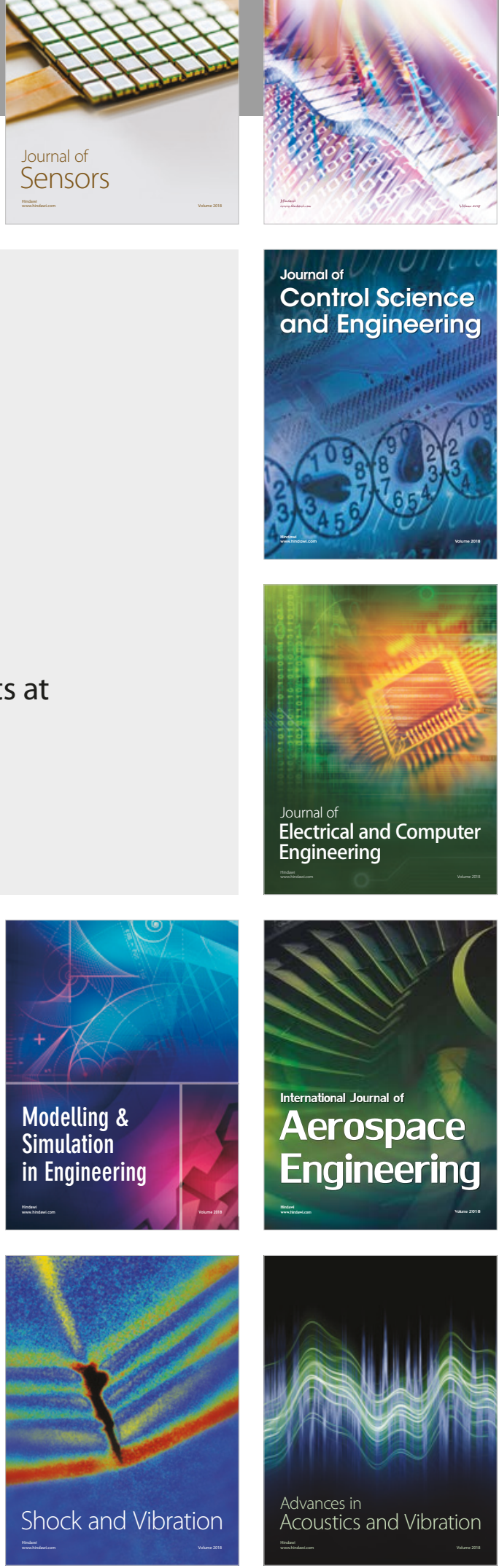